\title{
A Paisagem como categoria geográfica: Comportamento espectral de vegetação do alto curso da bacia hidrográfica do rio Catolé - Bahia
}

\section{The Landscape as a geographical category: Spectral behavior of vegetation in the upper course of the Catolé River basin - Bahia}

\section{El paisaje como categoría geográfica: comportamiento espectral de la vegetación del alto curso de la cuenca del río Catolé - Bahía}

\author{
Nielson Pereira da Silva Bonfim ${ }^{1}$ http://orcid.org/0000-0003-2048-7533 \\ Espedito Maia Lima ${ }^{2}$ http://orcid.org/0000-0003-1427-0098
}

\footnotetext{
${ }^{1}$ Mestrando do Programa de Pós Graduação em Geografia (PPGEO) - Universidade Estadual do Sudoeste da Bahia (UESB) nielsonpereira@gmail.com

${ }^{2}$ Doutor pelo Programa de Pós Graduação em Geografia - Universidade Federal de Sergipe (UFS) - Professor Titular de Geografia Física - Universidade Estadual do Sudoeste da Bahia (UESB) - espeditomaia@ gmail.com.
}

\section{Resumo}

O presente artigo e suas proposições metodológicas, tem como objetivo principal realizar a análise ambiental a partir da integração dos componentes naturais e elementos antrópicos, com respostas a alterações do ambiente delimitado ao longo de 10 anos. Para isto, adota-se o conceito de paisagem como categoria, que colabora no entendimento das relações sociais e naturais em um determinado espaço, e que por meio das atividades humanas pode-se observar as transformações físicas e antrópicas na natureza vivida. Foram realizados os trabalhos cartográficos a partir de imagens orbitais e através destas foram obtidos o NDVI e a análise visual da cobertura vegetal, mostrando que as ações modificadoras tiveram como fator primordial a ação antrópica.

Palavras-chave: Geossistema. Paisagem. Sensoriamento remoto.

\begin{abstract}
The main objective of this article and its methodological proposals is to carry out environmental analysis based on the integration of natural components and anthropic elements, with responses to changes in the environment delimited over 10 years. For this, the concept of landscape is adopted as a category, which collaborates in the understanding of social and natural relations in a given space, and that through human activities it is possible to observe the physical and anthropic transformations in the lived nature. Cartographic works were carried out using orbital images and through them the NDVI and the visual analysis of the vegetation cover were obtained, showing that the modifying actions had as an essential factor the anthropic action.
\end{abstract}

Keywords: Geosystem. Landscape. Remote sensing. 


\section{Resumen}

El objetivo del texto es presentar un análisis ambiental estableciendo como marco analítico la integración entre los componentes naturales y elementos antrópicos, con respuesta a la alteración del ambiente a lo largo de diez años. Así, es útil el concepto de paisaje como categoría que auxilia en la comprensión de las relaciones sociales y naturales en un determinado espacio, y por medio de las actividades humanas es posible observar las transformaciones físicas y antrópicas en la naturaleza vivida. Realizamos los trabajos cartográficos con imágenes orbitales y con las cuales fue posible obtener el NDVI y el análisis visual de la cobertura vegetal, señalando así que las acciones modificadoras tuvo como principal causa la acción antrópica.

Palabras clave: Geosistema. Paisaje. Detección remota.

Recebido em: 29/02/2020

Aceito para publicação em: 20/04/2020

\section{Introdução}

O termo paisagem conforme Zacharias (2006) originou-se do latim pagus (país), com sentido de lugar, unidade territorial. Nas línguas derivadas do latim surgiram os significados paisaje (do espanhol), paysage (do francês) e paesaggio (do italiano). A noção de paisagem, designada com o termo alemão Landschaft foi desenvolvida por Humboldt e posteriormente pelos sábios Dokuchaev, Passarge e Berg no século XIX e nos primeiros anos do século XX (RODRIGUEZ; SILVA, 2002). As escolas alemãs e russo-soviéticas embasaram a definição de paisagem, e na concepção de Augusto (2016) definiram-na como um complexo integrado formado por diferentes elementos, e tiveram importantes pensadores como Passarge (1919), Troll (1950), Riábchicov (1976), Sotchava (1978), dentre outros.

Nos anos 60, Sotchava utilizou a Teoria Geral dos Geossistemas (TGS) como elemento para formulação da proposta de estudos dos geossistemas. Conforme Rodriguez e Silva (2002), a paisagem era considerada uma formação sistêmica, formada por cinco atributos fundamentais: estrutura, funcionamento, dinâmica, evolução e informação. Desse modo, as diversas categorias dimensionais do geossistema - planetário, regional, topológico e intermediários - obedecem a critérios da espacialização geográfica e submetem-se às suas próprias escalas e peculiaridades qualitativas da organização geográfica (ROSS, 2006).

Especificamente se tratando de estudo de paisagem, Bernardino et al. (2018) enfatiza as concepções naturalistas de Humboldt e Dokuchaev, pois representam sínteses naturalistas mais rebuscadas e que influenciaram mais diretamente as concepções Bertrandianas. 
A Paisagem como categoria geográfica: Comportamento espectral de vegetação do alto curso da bacia hidrográfica do rio Catolé - Bahia

BONFIM, N. P. S.; LIMA, E. M.

O presente artigo e as suas proposições metodológicas permitiram a análise ambiental a partir da integração dos componentes naturais e elementos antrópicos, com respostas a alterações do ambiente delimitado ao longo de 10 anos. Esta atividade conjugada com os trabalhos voltados para cartografia de paisagem permitiu a avaliação do comportamento da cobertura florestal da área de estudo, com bases na análise geossistêmica para estudos da análise de paisagem.

No artigo é realizado o referencial teórico da pesquisa, destacando a categoria Paisagem e a importância de seus estudos na Geografia Física através da Teoria Geral dos Sistemas (TGS), que fundamentou os estudos propostos por Sotchava e as contribuições de Bertrand, através do estudo ambiental em diferentes escalas e unidades (inferiores e superiores), com relação dinâmica entre elementos físicos, biológicos e antrópicos, de forma indissociável e integrada, principalmente nas unidades inferiores (Geossistema, Geofáceis e Geótopo).

Após o entendimento teórico, foram realizados os trabalhos cartográficos, através do software QGIS, imagens orbitais dos satélites LANDSAT 5 e LANDSAT 8, obtidas através do site do Serviço Geológico dos Estados Unidos ou United States Geological Survey (USGS). Através destas imagens é obtido o Índice de Vegetação por Diferença Normalizada (NDVI) e a análise visual do comportamento da cobertura vegetal, pelo princípio da reflectância pelas bandas do vermelho $(\mathrm{R})$ e do Infravermelho (NIR).

\section{O conceito de paisagem e sua importância para estudos ambientais}

O conceito de paisagem em Geografia consiste em uma categoria que colabora no entendimento das relações sociais e naturais em um determinado espaço, e que por meio das atividades humanas, podem-se observar as transformações físicas e antrópicas na natureza vivida. Paisagem sob a ótica dos estudos ambientais trata-se de uma caracterização física, em que Schier o define sendo:

Uma representação do espaço geográfico, uma vez que sua flexibilidade de escala permite sua aplicação em vários níveis geográficos diferenciados, como o território, a região, a bacia hidrográfica, chegando ainda ao nível de um ecossistema, ou mesmo, de um elemento isolado no conjunto ecológico (SCHIER, 2003, p. 5).

De acordo com Maximiano (2004) esta resulta da relação dinâmica de elementos físicos, biológicos e antrópicos, e que ela não é apenas um fato natural, mas inclui a existência humana. 
A Paisagem como categoria geográfica: Comportamento espectral de vegetação do alto curso da bacia hidrográfica do rio Catolé - Bahia

BONFIM, N. P. S.; LIMA, E. M.

Sua concepção como uma totalidade dialética de base natural foi desenvolvida principalmente na União Soviética (RODRIGUEZ; SILVA, 2002). Conforme Bertrand:

É, em uma determinada porção do espaço, o resultado da combinação dinâmica, portanto instável de elementos físicos, biológicos e antrópicos que, reagindo dialeticamente uns sobre os outros, fazem da paisagem um conjunto único e indissociável, em perpétua evolução (BERTRAND, 2004, p. 141).

Em uma abordagem sistêmica, as informações temáticas como vegetação, relevo, aspectos edáficos e pedológicos, substrato geológico, isoladamente, não ajudam muito na compreensão das Unidades de Paisagem (AMORIM; OLIVEIRA, 2008). Para compreensão de seu funcionamento é necessário estudar estes elementos e suas conexões.

Segundo Santos e Souza (2011), ao considerar o estudo integrado dos componentes da paisagem, a análise geoambiental preconiza a avaliação da dinâmica dos ambientes naturais e dos transformados pelas intervenções das atividades antrópicas. O sistema Geossistema - Território Paisagem tem-se apresentado como uma importante ferramenta nesta análise.

Conforme Zacharias:

As diferentes teorias, paradigmas e procedimentos metodológicos utilizados pela Geografia para estudo e análise das paisagens culminam na Teoria Geral dos Sistemas - TGS, formalizada por Bertalanffy (1968) e ampliada por Chorley e Kennedy (1971) que trouxe o olhar sobre a paisagem analisando-a pela funcionalidade sistêmica (ZACHARIAS, 2006, p. 42 - 43).

O estudo da Fisiologia de Paisagem, proposto por Ab'Sáber, insere as ações cumulativas do homem como formadora da conjuntura dinâmica do espaço total, para entender o risco como elemento resultante desse processo morfodinâmico e matriz da formação de paisagens (CRUZ; COSTA, 2010).

Para Souza (2017), a Ecologia de Paisagem representa os avanços metodológicos e técnicos nos estudos da paisagem, assumindo concepções de análise multidisciplinar e integrada, incorporando as categorias estrutura, função e mudança.

Estudar a paisagem é antes de tudo apresentar um problema de método (BERTRAND, 2004). Cavalcanti e Viadana afirmam que a paisagem pode ser analisada:

Como formação natural, pela interação de componentes e elementos naturais, ocorrendo concepções distintas: como conceito de gênero de qualquer nível, utilizando-se como sinônimo os termos, complexo territorial natural ou geossistema natural; como interpretação regional, concebida como uma unidade taxonômica da regionalização físico-geográfica; e como interpretação tipológica 

A Paisagem como categoria geográfica: Comportamento espectral de vegetação do alto curso da bacia hidrográfica do rio Catolé - Bahia
BONFIM, N. P. S.; LIMA, E. M.

compreendida como um território com traços comuns (CAVALCANTI; VIADANA, 2007, p. 25 - 26).

Realizando a análise das três concepções apresentadas, Zacharias afirma que:

Mesmo apresentando concepções diferentes entre si, principalmente no que concerne ao enfoque da dinâmica da paisagem e sua representação cartográfica, todas essas teorias convergem para um ponto comum, a busca para sua explicação e sustentabilidade. Em todos os casos, a noção de espaço - e da inter-relação do homem com seu ambiente - está incutida na maior parte das definições (ZACHARIAS, 2006, p. 43).

Atualmente o conceito de "paisagem" está presente na ciência e na arte. Porém, somente a Geografia deu ao seu uso um valor científico, transformando-o em eixo de toda uma teoria de investigação (TROLL, 1997). A polissemia da noção de paisagem apresenta a possibilidade de leitura da expressão da interação sistemas naturais-sociais através da abordagem sistêmica (DIAS; SANTOS, 2007).

Os estudos visam não só os componentes da natureza em si mesmos, mas também as conexões a eles inerentes. Estas conexões se estabelecem por interações entre os componentes do meio físico, e conforme os pensamentos e obra do Geógrafo russo Sotchava, os geossistemas são formados por estas conexões e sem restrição, onde o autor formula os principais problemas caracterizando as atuais tarefas deste ramo:

a) Modelização de geossistemas à base de sua dinâmica espontânea e antropogênica e do regime natural a ela correspondente; b) Análise de axiomas e outros princípios de uma teoria especial de geossistemas como parte da teoria geral (metateoria) dos sistemas; c) Investigação de métodos racionais para a avaliação quantitativa de geossistemas e processos formadores da paisagem, particularmente do aparatus matemático adequado à sua descrição; d) Análise sistêmica das conexões espaciais no âmbito geográfico, a níveis planetários, regional ou topológico; e) Pesquisas sobre a condição (ou o estado) espacialtemporal dos geossistemas e montagem dos seus modelos geográficos, principalmente dos mapas do ambiente em conexão com os problemas de sua conservação e otimização; f) Estudo da influência dos fatores socioeconômicos no ambiente natural e prognose dos geossistemas do futuro; g) Exame geográfico de projetos para o complexo utilização-conservação do ambiente geográfico; $h$ ) Seleção, processamento e sistematização de informações referentes à paisagem natural para fins educacionais ou de pesquisa (SOTCHAVA, 1977, p. 03 - 04).

Embora os geossistemas sejam fenômenos naturais, todos os fatores econômicos e sociais, influenciando sua estrutura e peculiaridades espaciais, são tomados em consideração no seu estudo e suas descrições verbais ou matemáticas (SOTCHAVA, 1977). Por sua vez, a categoria paisagem 
A Paisagem como categoria geográfica: Comportamento espectral de vegetação do alto curso da bacia hidrográfica do rio Catolé - Bahia

BONFIM, N. P. S.; LIMA, E. M.

é tratada como base para compreensão dos processos transformadores do espaço, em função dos interesses e das necessidades dos indivíduos e comunidades (LIMA, 2012).

Quando analisa-se as paisagens sob influências antropogênicas, demonstram-se a complexidade dos estudos pelo dinamismo das mobilidades biológicas e também pelo que Bertrand (2004) cita de evolução própria do potencial ecológico que precede (geomorfogênese e degradação antrópica). Ainda segundo o autor, por essa dinâmica interna, o geossistema não apresenta, necessariamente, uma grande homogeneidade fisionômica.

\section{Uso das tecnologias de informação no estudo das paisagens em bacias hidrográficas.}

O Paradigma Geossistêmico proposto por Sotchava, que tomando base os princípios da TGS traz a necessidade de se analisar a paisagem pelas escalas taxonômicas, chegando-se a sua representação, através da chamada cartografia das paisagens (ZACHARIAS, 2006). Para o uso das tecnologias de representação, utilizam-se os produtos obtidos pelas Geotecnologias de informação, entre estes, o uso de sensoriamento remoto, ferramenta indispensável para estudo prático da representação da paisagem. Augusto informa que:

Com grande potencial de aplicabilidade na temática ambiental, os produtos obtidos por meio da tecnologia do Sensoriamento Remoto, como imagens de radar e imagens multiespectrais, vêm sendo extensamente utilizados nos últimos anos, tendo apresentado um grande crescimento em razão da expansão dos meios de processamento, dos baixos custos de capital, e pelo fato das imagens possuírem variadas escalas de tempo e de detalhamento espacial (AUGUSTO, 2016, p. 146).

Para a interpretação e análise da paisagem na bacia hidrográfica do alto curso da bacia hidrográfica do rio Catolé, utilizou-se como elemento de avaliação da região, o comportamento espectral da vegetação existente, em uma determinada escala temporal definida, a partir de diversos índices conhecidos.

O índice mais utilizado atualmente para este tipo de avaliação tem sido o Índice de Vegetação por Diferença Normalizada ou Normalized Difference Vegetation Index (NDVI), que se utiliza de formula matemática específica, tendo como referência a razão entre a reflectância no infravermelho próximo (NIR) e a reflectância no vermelho $(\mathrm{R})$, variando entre -1 e +1 . Quanto mais próximo de +1 , maior a cobertura vegetal existente, em níveis que podemos classificar como estágio avançado de regeneração ou estágio de preservação de vegetação. 
A Paisagem como categoria geográfica: Comportamento espectral de vegetação do alto curso da bacia hidrográfica do rio Catolé - Bahia

BONFIM, N. P. S.; LIMA, E. M.

No Mapa 1 observa-se o alto curso da bacia no ano de 2009 e a representação do índice vegetativo, utilizando o satélite LANDSAT 5 como instrumento para captação de imagem orbital. O LANDSAT 5 é equipado com o sensor LANDSAT Enhanced Thematic Mapper Plus (ETM +) de 15 a 30 metros de resolução.

Na imagem há uma considerável representação da classe com valor de 0,4338 (verde claro), o que indica provavelmente uma ação antrópica anterior para supressão florestal em grandes proporções, se compararmos somente o limite geográfico da bacia, e a substituição destas por atividades agrícolas predominantes, como a cafeicultura e pastagem. Esta afirmativa é possível com frequentes visitas em campo e histórico da agricultura na região.

Mapa 1 - Índice vegetativo do alto curso da bacia hidrográfica do rio Catolé (NDVI), 2009.

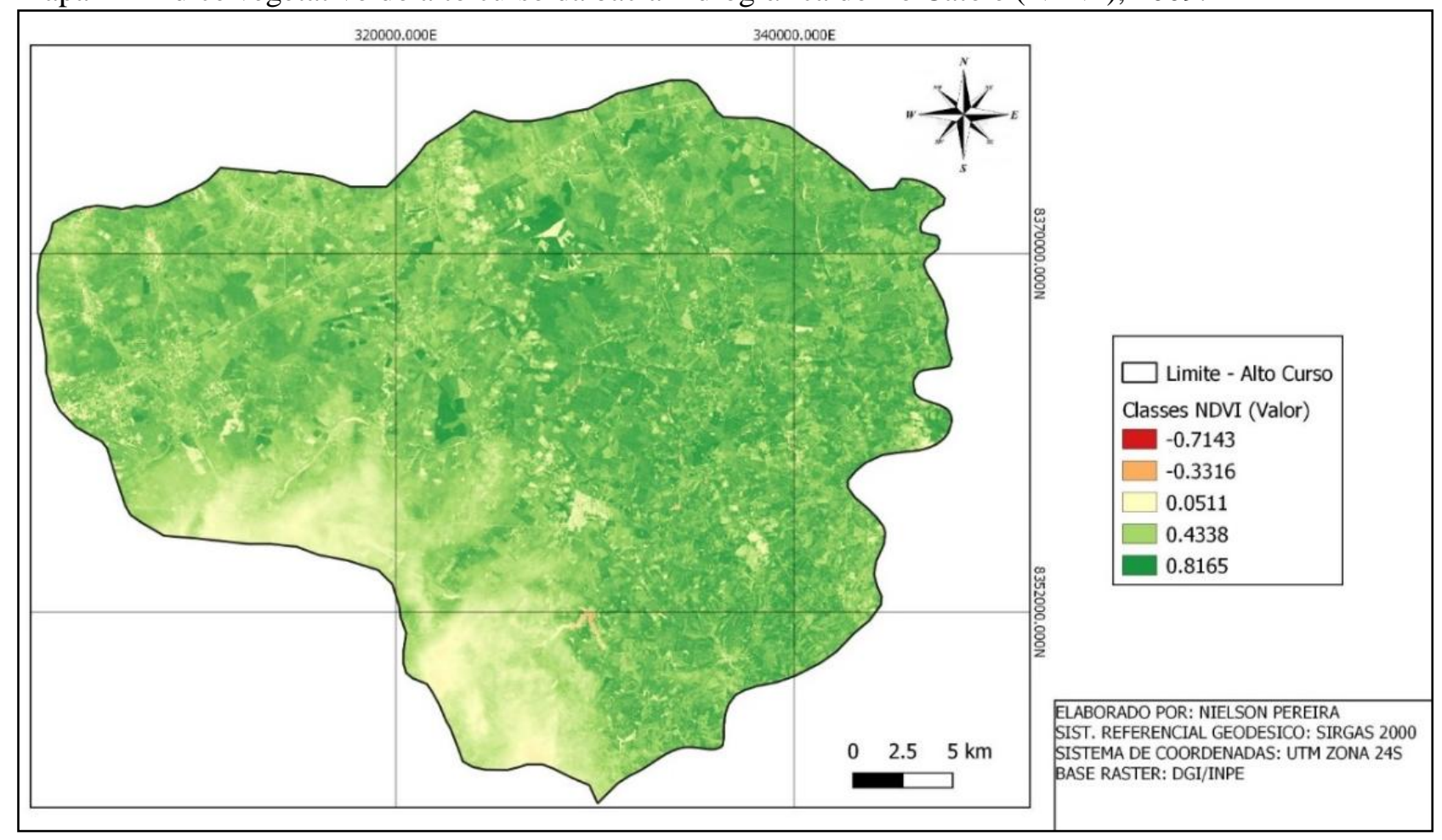

Fonte: Ferreira (2019)

Para o Mapa 2, se compararmos com a realidade avaliada em 2009, houve uma significativa mudança espectral durante a captação da imagem, principalmente na região oeste e noroeste da bacia hidrográfica. A região que, provavelmente em 2009 predominava o cultivo de pastagens e olericultura, cedeu espaço a loteamentos rurais, aumento da área urbana na sede municipal de Vitória da Conquista e seus distritos e povoados, como os distritos de José Gonçalves e São Sebastião e o bairro Lagoa das Flores. Para a captação da imagem em 2019 utilizou-se do satélite LANDSAT 8, com imagens ortorretificadas e todos os produtos em formato GEOTIFF. 
A Paisagem como categoria geográfica: Comportamento espectral de vegetação do alto curso da bacia hidrográfica do rio Catolé - Bahia

BONFIM, N. P. S.; LIMA, E. M.

Para o referido mapa, a cor verde escura $(0,5858)$ representa as vegetações existentes em estágio avançado de recuperação ou em bom estágio de conservação; o verde claro $(0,4215)$ representa matas em estágios iniciais de recuperação e atividades agrícolas; o amarelo $(0,2571)$ caracteriza no mapa o solo exposto; cor laranja $(0,0928)$ representa a existência no mapa de aglomerados e edificações urbanas; e a cor vermelha (-0,0716) a reflectância de corpos hídricos, com destaque para as barragens de Água Fria I e II, representadas na porção sul da bacia hidrográfica.

Mapa 2 - Índice vegetativo do alto curso da bacia hidrográfica do rio Catolé (NDVI), 2019.

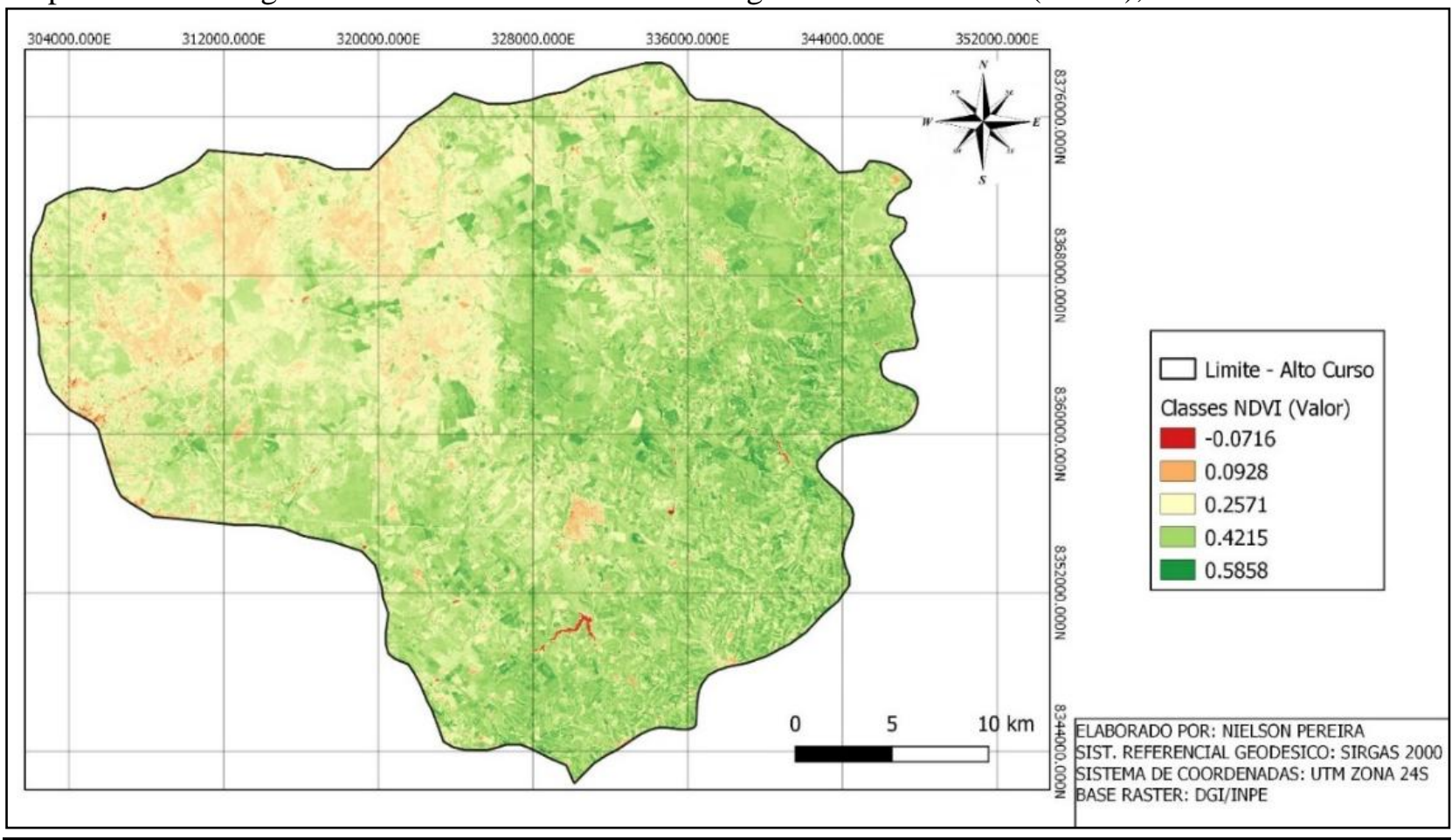

Fonte: Ferreira (2019)

Se em um ecossistema se altera ou se destrói a vegetação como consequência de um fato natural ou artificial, de uma forma espontânea modifica-se toda a estrutura geográfica e todas as interações dos elementos da paisagem (TROLL, 1997). Amorim e Oliveira (2008) tratam este fenômeno como degradação geoecológica, que define-se como a perda de atributos e propriedades sistêmicas que garantem o cumprimento das funções geoecológicas e a atividade dos mecanismos de auto regulação. Este processo de degradação se subdivide em processos geoecológicos naturais (erosão, degradação de pastagens, perda da biodiversidade) e processos geoecológicos de interação (contaminação do solo, contaminação das águas, alteração dos recursos hídricos). 


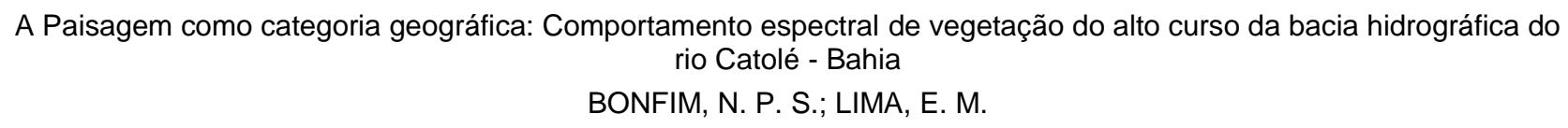

\section{Considerações finais}

Os resultados obtidos através das imagens captadas e a análise ambiental do alto curso da bacia hidrográfica do rio Catolé mostram que as ações dinâmicas e integradas, explicam em boa parte as mudanças ocorridas no espaço ao longo de 10 anos, tendo como fator primordial a ação antrópica para ampliação de aglomerados urbanos, ampliação das áreas agrícolas e uso da água como fonte de recursos hídricos para irrigação, abastecimento humano e dessedentação animal.

Os fatores climáticos, envolvendo variáveis como temperatura $\left({ }^{\circ} \mathrm{C}\right)$, umidade $(\%)$, precipitação pluviométrica $(\mathrm{mm})$, razão de insolação (horas) e velocidade dos ventos $(\mathrm{m} / \mathrm{s})$, também interferem na composição da paisagem, principalmente por tratarmos de uma região localizada no semiárido e possuir plantas caducifólias, embora estes elementos não tenham sido objeto de análise durante a pesquisa.

Percebe-se nas imagens captadas uma expansão urbana na região noroeste da área de estudo com avançado estágio, sem qualquer compensação ambiental para preservação do meio físico e biológico. A desproporcionalidade entre áreas antrópicas e áreas sob sistemas naturais é evidente, podendo avaliar na imagem que as áreas em verde escuro nos mapas apresentados sempre são minorias.

Faz-se necessário realizar um ordenamento territorial e organização da gestão e uso dos recursos naturais, através da criação de um comitê gestor, aparelhamento do órgão estadual ambiental (INEMA), conscientização e cumprimento das legislações pertinente para conservação de àreas de preservação permanente (APP), reserve legal (RL) e uso consciente da água como bem finito e dotado de valor econômico.

\section{Referências:}

AMORIM, R. R.; OLIVEIRA, R. C. de. As unidades de paisagem como uma categoria de análise geográfica: O exemplo do município de São Vicente - SP. Sociedade \& Natureza, Ano 20, n. 2, Uberlândia - MG: 2008.

AUGUSTO, R. C. A cartografia de paisagens e a perspectiva geossistêmica como subsídios ao planejamento ambiental. Revista Tamoios, Ano 12, n. 1, São Gonçalo - RJ: 2016.

BERNARDINO, D. S. M.; OLIVEIRA, A. M.; DINIZ, M. T. M. Georges Bertrand e a análise integrada da paisagem em Geografia. REGNE, v. 4, n. 2. Caicó - RN: 2018.

BERTRAND, G. Paisagem e Geografia física global. Esboço metodológico. Revista RA'E GA, n. 8, Curitiba - PR: 2004. 
A Paisagem como categoria geográfica: Comportamento espectral de vegetação do alto curso da bacia hidrográfica do rio Catolé - Bahia

BONFIM, N. P. S.; LIMA, E. M.

CAVALCANTI, A. P. B.; VIADANA, A. G. Organização do espaço e análise da paisagem. Rio Claro: UNESP - IGCE, 2007.

CRUZ, D. R.; COSTA, R. C. Fisiologia da paisagem e riscos. In: Seminário Latino-Americano de Geografia Física, VI. Seminário Ibero-Americano de Geografia Física, II, 2010, Coimbra. Anais... Coimbra: Universidade de Coimbra, 2010.

DIAS, J.; SANTOS, L. A paisagem e o geossistema como possibilidade de leitura da expressão do espaço sócio-ambiental rural. Revista Franco-brasileira de Geografia, v. 1, n. 1, 2007.

LIMA, E. M. Interações socioambientais na bacia hidrográfica do rio Catolé - Bahia. Tese de doutorado apresentado ao Programa de Pós Graduação em Geografia da Universidade Federal de Sergipe, UFS, 2012, 280p.

MAXIMIANO, L. A. Considerações sobre o conceito de paisagem. Revista RA'E GA, n. 8, Curitiba: 2004.

RODRIGUEZ, J. M. M.; SILVA, E. V. da. A classificação das paisagens a partir de uma visão geossistêmica. Mercator. Revista de Geografia da UFC, Ano 1, n. 1, Fortaleza: 2002.

ROSS, J. Ecogeografia do Brasil: subsídios para planejamento ambiental. São Paulo: Oficina de Textos, 2006. 208p.

SANTOS, J. O. S.; SOUZA, M. J. N. de. Impactos ambientais e riscos de ocupação na bacia hidrográfica do Rio Cocó - Ceará./ In: SILVA, E. V. da; RODRIGUEZ, J. M. M.; MEIRELES, A. J. A (Org.). Planejamento Ambiental e Bacias Hidrográficas. Fortaleza: Edições UFC, 2011. $149 \mathrm{p}$.

SCHIER, R. A. Trajetórias do conceito de paisagem na Geografia. Revista RA'E GA, n. 7, Curitiba: 2003.

SOTCHAVA, V. B. O Estudo de Geossistemas. Métodos em Questão (16). São Paulo: IGEO/USP, 1977.

SOUZA, J. C. de. Metodologia para avaliação ambiental em bacias hidrográficas, utilizando técnicas de geoprocessamento e sensoriamento remoto. Tese de doutorado apresentado ao Programa de Pós Graduação em Ciências Ambientais da Universidade Estadual Paulista "Júlio de Mesquita Filho", UNESP, 2017, 95p.

TROLL, C. A paisagem geográfica e sua investigação. Espaço e Cultura, n. 4, 1997.

ZACHARIAS, A. A. A representação gráfica das unidades de paisagem no zoneamento ambiental: um estudo de caso no município de Ourinhos - SP. Tese de doutorado apresentado ao Programa de Pós Graduação em Geografia da Universidade Estadual Paulista, UNESP. 2006. 209p. 